\title{
Attenuated Salmonella Typhimurium Lacking the Pathogenicity Island-2 Type 3 Secretion System Grow to High Bacterial Numbers inside Phagocytes in Mice
}

\author{
Andrew J. Grant*, Fiona J. E. Morgan, Trevelyan J. McKinley, Gemma L. Foster, Duncan J. Maskell \\ Pietro Mastroeni"
}

Department of Veterinary Medicine, University of Cambridge, Cambridge, United Kingdom

\begin{abstract}
Intracellular replication within specialized vacuoles and cell-to-cell spread in the tissue are essential for the virulence of Salmonella enterica. By observing infection dynamics at the single-cell level in vivo, we have discovered that the Salmonella pathogenicity island 2 (SPI-2) type 3 secretory system (T3SS) is dispensable for growth to high intracellular densities. This challenges the concept that intracellular replication absolutely requires proteins delivered by SPI-2 T3SS, which has been derived largely by inference from in vitro cell experiments and from unrefined measurement of net growth in mouse organs. Furthermore, we infer from our data that the SPI-2 T3SS mediates exit from infected cells, with consequent formation of new infection foci resulting in bacterial spread in the tissues. This suggests a new role for SPI-2 in vivo as a mediator of bacterial spread in the body. In addition, we demonstrate that very similar net growth rates of attenuated salmonellae in organs can be derived from very different underlying intracellular growth dynamics.
\end{abstract}

Citation: Grant AJ, Morgan FJE, McKinley TJ, Foster GL, Maskell DJ, et al. (2012) Attenuated Salmonella Typhimurium Lacking the Pathogenicity Island-2 Type 3 Secretion System Grow to High Bacterial Numbers inside Phagocytes in Mice. PLoS Pathog 8(12): e1003070. doi:10.1371/journal.ppat.1003070

Editor: Denise M. Monack, Stanford University School of Medicine, United States of America

Received July 26, 2012; Accepted October 19, 2012; Published December 6, 2012

Copyright: (c) 2012 Grant et al. This is an open-access article distributed under the terms of the Creative Commons Attribution License, which permits unrestricted use, distribution, and reproduction in any medium, provided the original author and source are credited.

Funding: This work was supported by a Medical Research Council (MRC) grant G0801161 awarded to AJG, PM and DJM. TJM was supported by the Department for the Environment, Food and Rural Affairs/Higher Education Funding Council of England (grant number VT0105). GLF was supported by a Wellcome Trust PhD training studentship. The funders had no role in study design, data collection and analysis, decision to publish, or preparation of the manuscript.

Competing Interests: The authors have declared that no competing interests exist.

* E-mail: ajg60@cam.ac.uk

- These authors are joint senior authors on this work.

\section{Introduction}

Infection of a host by a bacterium is a dynamic process that can be measured and analyzed at different scales. Many experimental systems for understanding infection measure the overall increase or decrease in numbers of bacteria in different organs in the host over time. Often, fine-structure dynamics of the interactions between bacteria and host cells are measured using ex vivo or in vitro systems, and these results are used to infer mechanisms that explain net patterns of survival in vivo. Most of these inferences have not been tested experimentally in whole-animal models of infection. It is clear that similar overall net survival patterns in organs might be derived from very different underlying processes. For example, an apparent net lack of growth could arise when a bacterium grows very slowly or not at all in an organ over a period of time, or it could arise from a bacterium replicating quickly but also being killed at a similar rate, giving the appearance of a net lack of growth. Unraveling these complex underlying infection dynamics is important for a full understanding of the hostpathogen interaction, and is crucially important if intervention and prevention strategies are to be improved and applied to maximum effect.

An ideal model system with which to study these fundamental dynamic mechanisms in vivo is provided by invasive Salmonella enterica serovar Typhimurium infections of mice. In this system the bacteria live within spleen and liver phagocytes [1] and replicate inside a specialized, membrane-bound vacuole: the Salmonellacontaining vacuole (SCV). Wild-type salmonellae in susceptible mice grow rapidly in the organs, at a net rate approximating to a ten-fold increase per day. On the other hand, live attenuated vaccine strains containing mutations in defined genes show extremely slow or no net growth, and then are cleared from the organs, in the process stimulating protective immunity. Of particular interest here are those vaccine strains that are mutated in the same genes as new vaccine candidates being tested in the field for protection of humans against typhoid fever caused by $S$. Typhi. Prime examples are mutants that lack the type 3 secretion system (T3SS) encoded by Salmonella Pathogenicity Island 2 (SPI-2) [2].

In S. enterica, as in other bacterial species, T3SSs have evolved to deliver proteins from the bacterium into the host cell [3]. SPI-2 T3SS is required for replication of $S$. Typhimurium in some cell lines in vitro [4-7], and a reasonable assumption from this is that SPI-2 is also required for intracellular replication of salmonellae in the host animal $[5,6,8]$. This idea is supported by the fact that mutants lacking SPI-2 survive in the livers and spleens of infected animals, but show limited or no net growth in numbers $[5,8,9]$.

Previously, we have used multi-color fluorescence microscopy (MCFM) to image host cells in histological sections of infected mouse organs, counting the number of bacteria per cell and the distribution of infected cells throughout infected organs. This is a direct way of observing fine-structure infection dynamics cell-by- 


\section{Author Summary}

High quality science has been published concerning the dynamics of infectious disease spread through communities of people or animals, but less work has been done to understand infectious disease dynamics within the host. Many conclusions about how infectious agents work are based on experiments in isolated monocultures of cells or in somewhat crude experiments in whole animals. Understanding this complex process in whole animals is the next major challenge for infectious disease biologists, and is required if intervention strategies to prevent and cure infectious diseases are to be improved and targeted effectively. Bacteria of the species Salmonella enterica are a threat to public health, causing a wide range of lifethreatening diseases in humans and animals world-wide. In vitro cell experiments and inference from measuring net growth kinetics in mouse organs suggest that intracellular replication of $S$. enterica requires proteins delivered by the Salmonella pathogenicity island 2 (SPI-2) type 3 secretion system (T3SS) and that mutants in SPI-2 cannot replicate efficiently intracellularly. However, by observing directly infection dynamics at the single-cell level in vivo, we show that SPI-2 T3SS mutants can replicate to high intracellular densities in phagocytes in the organs of infected animals, but appear unable to leave infected cells.

cell, and it reveals the intracellular bacterial growth dynamics that underpin the net dynamics observable at the whole organ level. We found that when wild-type salmonellae are replicating rapidly in the organs, the number of bacteria per infected phagocyte is unexpectedly low and remains low [10-13]. Consequently, as the infection progresses and viable bacterial numbers per organ increase, the bacteria must undergo only a few replication cycles before they escape from the originally infected cells and disperse to infect new cells, where new infection foci emerge and the cycle repeats itself [10-15].

We used this more sophisticated understanding of the dynamics of growth of salmonellae in murine organs to address the hypothesis that SPI-2 is required for intracellular growth of the bacteria in vivo. Based on our previous studies, we predicted that a mutant lacking the SPI-2 T3SS would be present in the organs at the very low intracellular densities typical of slowly dividing strains $[10,11]$. However, we show that SPI-2 T3SS mutants can replicate to high intracellular densities in the spleens and livers of infected animals, but appear less able to leave infected cells than wild-type salmonellae, restricting bacterial dispersal through the tissues and dramatically reducing the formation of new foci of infection in the tissues.

\section{Results}

\section{SPI-2 T3SS mutants are present at higher densities per cell on average than the wild-type}

Initially we studied a mutant of $S$. Typhimurium strain NCTC 12023 (S12023) lacking the ssaV gene [16], which is unable to assemble the SPI-2 secretory machinery [17] (Figure 1A). The overall net growth of this mutant in infected organs is dramatically reduced compared with the wild-type parent, as determined by colony counts on organ homogenates [6,7]. The wild-type exhibited the expected infection dynamics at the cellular level, with low numbers of bacteria per cell at $72 \mathrm{~h}$ post infection (p.i.) (Figure 1B), despite rapid net growth per organ, this being entirely consistent with our previous findings [10-13]. On the other hand, most unexpectedly, at $72 \mathrm{~h}$ p.i. the $s s a V$ mutant was present at high numbers of bacteria per cell (Figure 1C) and was much less dispersed throughout the tissue than the wild-type bacteria.
This was very surprising. We expected it to be distributed mostly as one bacterium per cell.

To test whether this observation was generally true and not limited to the bacterial strain used, we repeated the analysis using ssaV mutants in two other strains (SL1344 and C5), and observed similar results, with, on average, high numbers of ssa $\mathrm{V}$ mutant bacteria per cell (data not shown).

To investigate whether these observations were the result of the ssa $V$ mutation specifically, or whether this pattern was a general phenomenon, we studied a different SPI-2 mutant lacking sseB (SseB forms part of the SPI-2 T3SS translocon) (Figure 1A). S12023 sseB [5] and S12023 ssaV behaved similarly in terms of slow-to-negligible net growth per organ in vivo, apparently paradoxically high intracellular densities (Figure 1D), and relative lack of dispersal throughout the tissues. Complementation of $s s e B$ using plasmid psseB [5] resulted in the intracellular densities and intra-organ dispersal pattern returning to wild-type (Figure 1E).

To ensure that the SPI-2 T3SS mutants being observed were indeed intracellular and not simply aggregated around the outside of the cell, we used confocal microscopy, staining for markers for phagocyte cell membranes. Three-dimensional reconstruction of these images showed that the bacteria were completely enclosed within phagocyte membranes, and that they are therefore intracellular (data not shown). Thus mutants lacking SPI-2 T3SS can grow to high numbers in some infected cells in vivo, despite having a low net growth pattern per organ.

Given that these results were very unexpected, we proceeded with a deep and rigorous quantification of intracellular bacterial densities in the tissues of mice infected with wild-type S12023, S12023 sseB, or the complemented $\mathrm{S} 12023$ sseB(psseB). We therefore compared, at $72 \mathrm{~h}$ p.i., the overall net levels of viable bacteria per liver or spleen (Figure $1 \mathrm{~F}$ ) with underlying bacterial loads within $\mathrm{CD}^{+}{ }^{+}$phagocytes (Figure $1 \mathrm{G}$ ). Because of the markedly different net growth rates per organ of the wild-type and mutant bacteria, different initial doses of bacteria were used to ensure that the total number of bacteria per organ per strain would be similar at $72 \mathrm{~h}$ p.i.. To assess formally the intracellular bacterial distributions between the strains, proportional odds ratios (ORs) and 95\% credible intervals were generated from a Bayesian ordinal regression model (for more details see Supporting Information - Protocol S1). At 72 h p.i. the intracellular bacterial distributions of the wild-type bacteria and the complemented mutant were both as expected, based on our previous work [1013], with intracellular densities heavily skewed towards low numbers (Figure 1G, Figure S1 and Table S1). Conversely, despite its low net growth rate per organ (Figure 1F), there is clear evidence that S12023 sseB-infected phagocytes are more likely to have higher intracellular bacterial densities than the wild-type or complemented strains (Figure $1 \mathrm{G}$, Figure S1 and Table S1).

Our data support the hypothesis that SPI-2 T3SS mutant bacteria can multiply inside phagocytes. To account for the low overall net bacterial growth per organ, this replication may occur in fewer cells, may be slower or may initiate at wild-type rate and then slow down or stop as bacterial numbers per cell become high (the latter density-dependent scenario being predicted in our previous mathematical models [11]).

\section{SPI-2 T3SS mutants are present in far fewer infected foci per organ than the wild-type}

The higher intracellular densities combined with our initial observations that SPI-2 T3SS mutant bacteria are less dispersed in the tissues were suggestive of a role for SPI-2 T3SSs as a mediator of bacterial escape from infected cells, dispersion through infected tissues and increase in the number of infection foci. To investigate this, we 
A

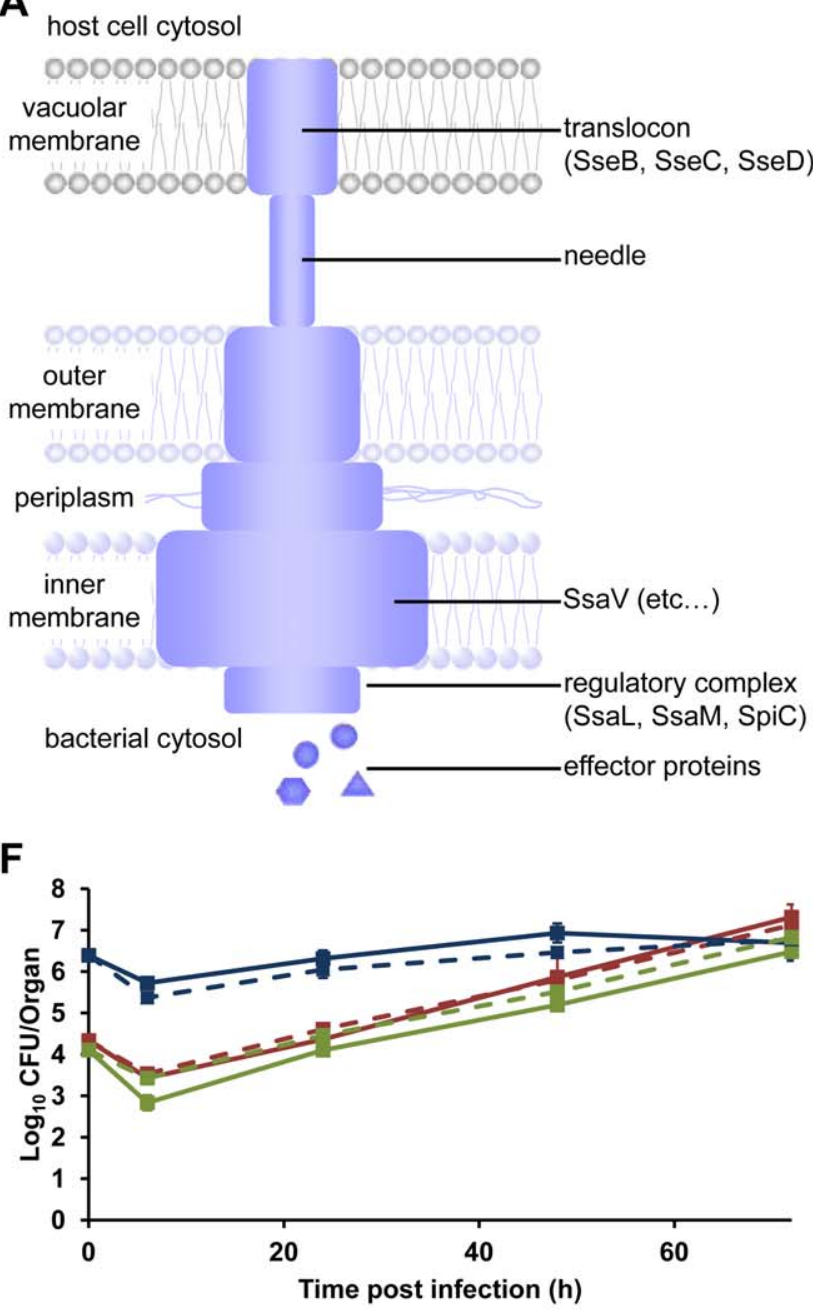

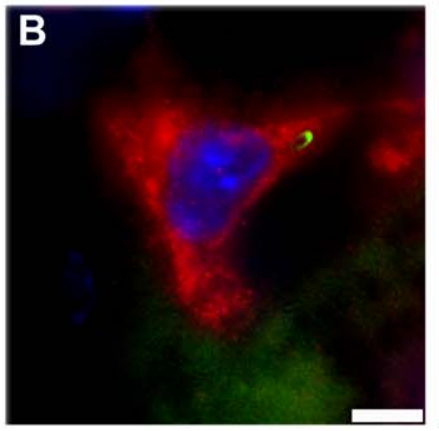
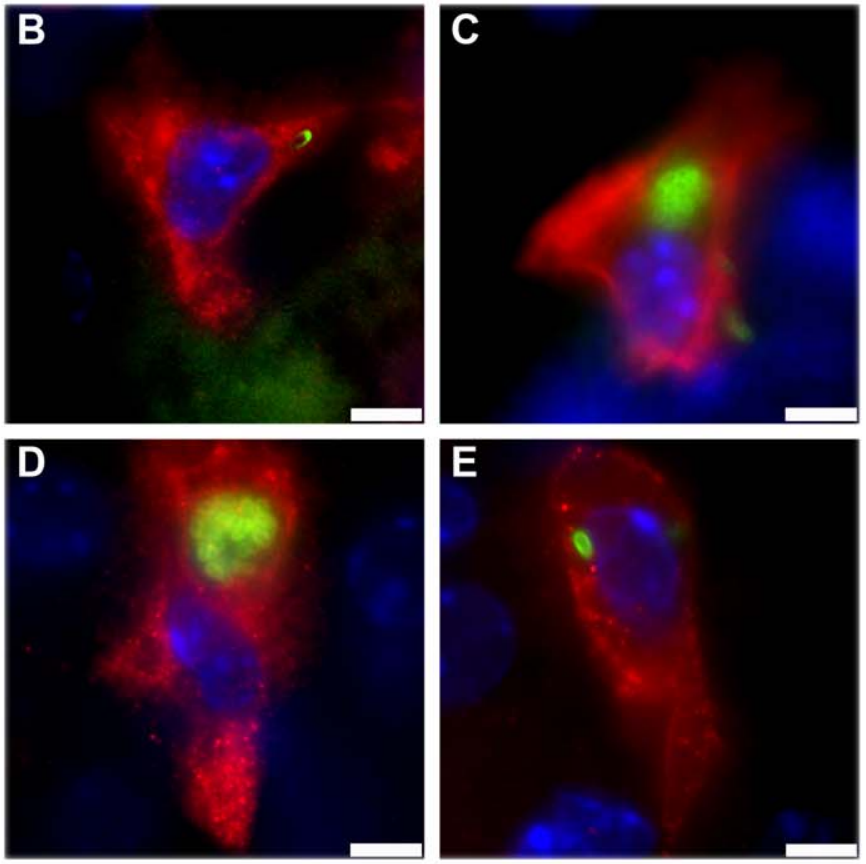

G

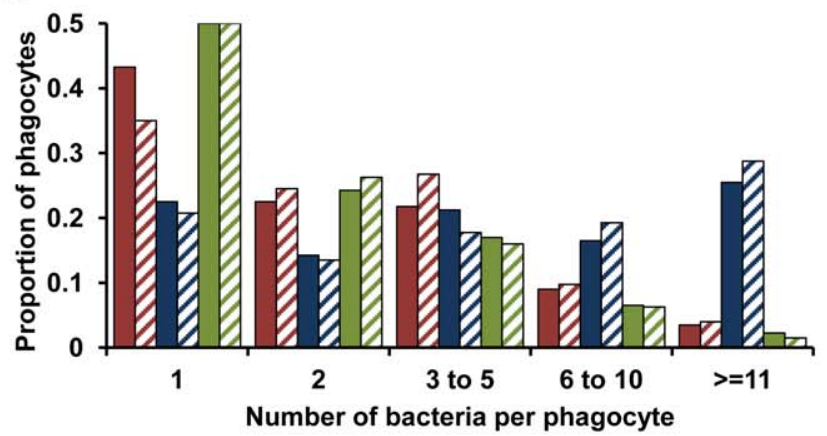

Figure 1. SPI-2 T3SS mutants can grow to high intracellular densities in CD18 ${ }^{+}$cells in vivo. (A) Model of the SPI-2 T3SS. SseB forms part of the translocon; SsaV is located in the inner membrane. (B-E) Representative fluorescence micrographs of Salmonella within phagocytes in infected livers of C57BL/6 mice at $72 \mathrm{~h}$ p.i. (B) S12023; (C) S12023 ssaV; (D) S12023 sseB; (E) S12023 sseB(psseB) [CD18 ${ }^{+}$cells (red), Salmonella (green), nucleic acid is stained with DAPI (blue), scale bars, $5 \mu \mathrm{m}]$. (F and G) C57BL/6 mice were infected i.v. with $\sim \log _{10} 4.3 \mathrm{CFU}\left(=2.15 \times 10^{4} \mathrm{CFU}\right)$ of S12023, $\sim \log _{10} 6.4 \mathrm{CFU}\left(=2.45 \times 10^{6} \mathrm{CFU}\right)$ of $\mathrm{S} 12023 \mathrm{sseB}$, or $\sim \log _{10} 4.1 \mathrm{CFU}\left(=1.27 \times 10^{4} \mathrm{CFU}\right)$ of $\mathrm{S} 12023 \mathrm{sseB}$ (psseB). (F) Net bacterial numbers in livers (unbroken lines) and spleens (dotted lines) were determined between 6 to $72 \mathrm{~h}$ p.i. from 4 mice per strain per time point (results are expressed as mean $\log _{10}$ viable count \pm standard deviation). (G) The proportion of infected phagocytes relative to the number of bacteria contained within each phagocyte is shown for livers (solid bars) and spleens (diagonal shading) at $72 \mathrm{~h}$ p.i. based on the counts obtained from 400 infected phagocytes per strain, from tissue obtained from 4 mice per strain [S12023 - red; S12023 sseB - blue; S12023 sseB(psseB) - green]. doi:10.1371/journal.ppat.1003070.g001

quantified the number of infected cells per field-of-view throughout the tissues at 72 h p.i. (Figures $2 \mathrm{~A}-\mathrm{D}$ ). The $s s e B$ mutant was substantially less dispersed throughout the tissue than the wild-type or complemented bacteria (Figures 2A-D, Figure S2 and Table S2). The wildtype bacteria and the complemented mutant had formed many more infection foci than the S12023 sseB mutant (Figures 2A-D, Figure S2 and Table S2) despite there being similar total bacterial numbers in the tissues at this time (Figure $1 \mathrm{~F}$ ). There was a small decrease in the number of infection foci between $0.5 \mathrm{~h}$ p.i. and $72 \mathrm{~h}$ p.i. in animals infected with the S12023 sseB mutant further confirming the impaired dispersion of this strain (Figure 2E, Figure S2 and Table S2).

As further corroboration of our data we generated a mutant lacking spiC, which is essential for SPI-2 T3SS protein secretion and effector translocation by interacting with $\mathrm{SsaM}$ and $\mathrm{SsaL}$ (Figure 1A), themselves encoded within the spi-2 locus [18-21]. Some studies have proposed that $\mathrm{SpiC}$ may be exported by the
SPI-2 T3SS into the host cell cytosol [22], where it interacts with host proteins, TassC [23] and Hook3 [24], which are implicated in cellular trafficking and the activation of signal transduction pathways [25-28]. We found that a mutant lacking spiC gave a similar phenotype to the $s s e B$ and $s s a V$ mutants in terms of intracellular bacterial densities and tissue dispersion (Figure S3 and Table S2). In addition, we found that an ssaM mutant had similar intracellular bacterial densities to a spiC mutant (data not shown).

The SPI-2 T3SS mutants (ssaV, sseB, spiC, ssaM) are therefore present in far fewer infected cells per organ but at higher densities per cell than the wild-type.

SPI-2 T3SS mutants seem unable to exit infected cells and form new infection foci in vivo

The accumulation of SPI-2 T3SS mutant bacteria inside cells is most likely explained by the intracellular replication of an infecting 

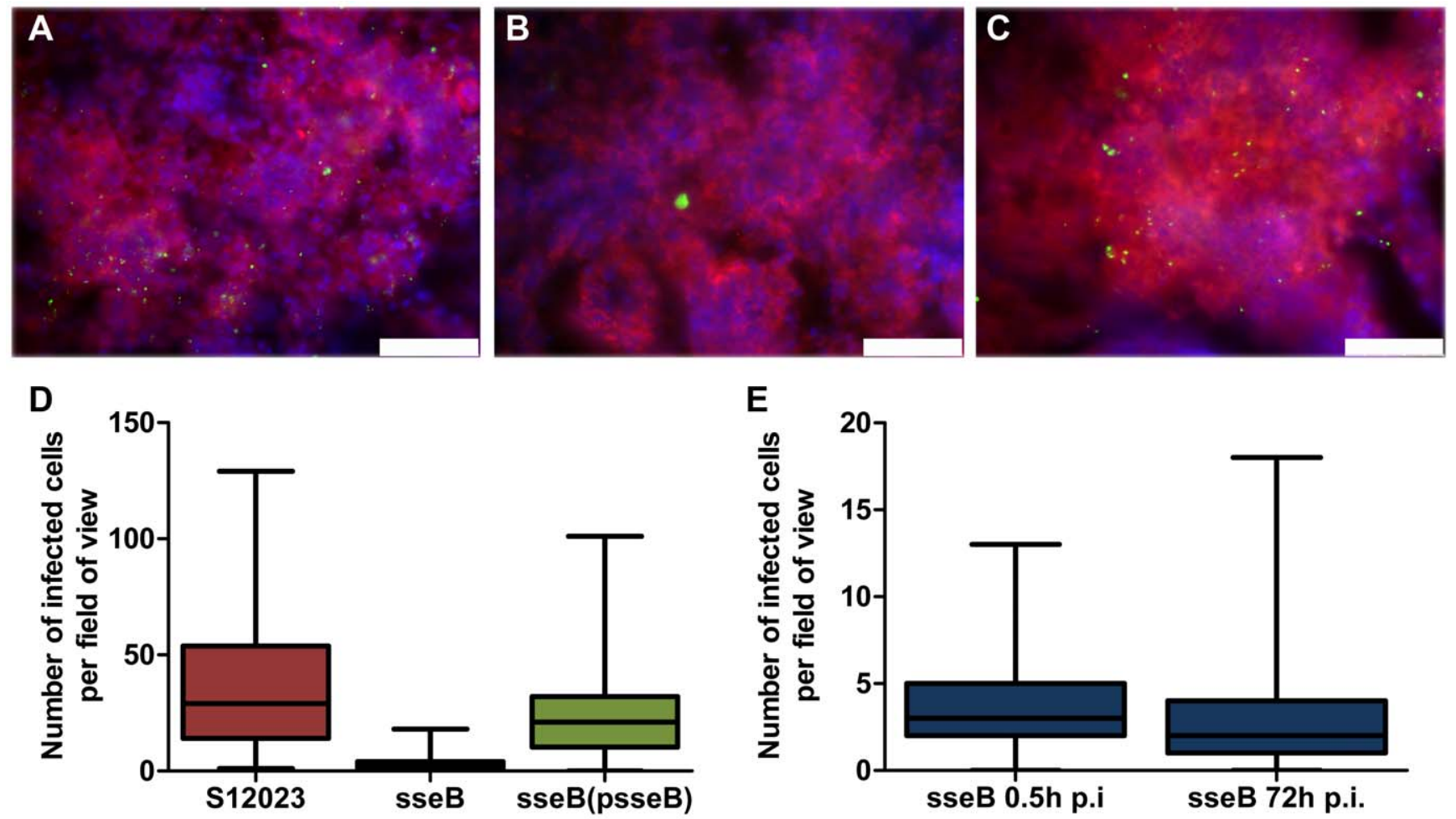

Figure 2. SPI-2 T3SS mutants are present in far fewer infected foci per organ than the wild-type. (A to C) Representative fluorescence micrographs of Salmonella within phagocytes in infected livers of C57BL/6 mice at $72 \mathrm{~h}$ p.i.. (A) S12023; (B) S12023 sseB; (C) S12023 sseB(psseB) [CD $18^{+}$cells (red), Salmonella (green), nucleic acid is indicated by DAPI (blue), scale bars, $\left.75 \mu \mathrm{m}\right]$. (D and E) Box and whisker plots showing the median, interquartile range and maximum and minimum number of infected cells per field-of-view in spleens for (D) S12023, S12023 sseB and S12023 sseB p(sseB) at $72 \mathrm{~h}$ p.i., obtained from 100 random fields from 4 mice for S12023 and S12023 sseB(psseB) infected tissue and 200 random fields from 7 mice for S12023 sseB infected tissue, and (E) S12023 sseB at 0.5 and $72 \mathrm{~h}$ p.i., obtained from 100 random fields from 3 mice for S12023 sseB infected tissue at $0.5 \mathrm{~h}$ p.i., and 200 random fields from 7 mice for $\mathrm{S} 12023 \mathrm{sseB}$ infected tissue at $72 \mathrm{~h}$ p.i. doi:10.1371/journal.ppat.1003070.g002

bacterium, but all other possible explanations had to be explored before this unexpected mechanism could be supported.

The first possibility tested was that the high intracellular densities seen with the SPI-2 T3SS mutants depended on phagocytes taking up clumps of bacteria. Groups of mice were infected with the same dose of the wild-type or the mutant bacteria. At $0.5 \mathrm{~h}$ p.i., when there is no evidence of any discernible bacterial growth or death [14], most of the bacteria within CD18 ${ }^{+}$ phagocytes were present as a single bacterium per cell with negligible differences in the intracellular bacterial distributions between any of the strains (Figure 3A, Figure S1 and Table S1). This is consistent with individual resident macrophages taking up single bacterial cells from the blood and eliminates the clumping hypothesis.

We proceeded with a rigorous quantification of intracellular bacterial densities in the tissues of mice infected with S12023 sseB, and discovered that he proportion of host cells containing large numbers of intracellular bacteria increased with time during an infection (Figure 3B, Figure S4 and Table S1). In addition, the number of bacteria in the heavily infected cells increased with time, with some of the heavily infected cells containing $\sim 100$ bacteria at $72 \mathrm{~h}$ p.i. (data not shown). This data is consistent with the bacteria growing inside the cell.

Alternatively, although extremely unlikely, high intracellular numbers could be reached by phagocytic cells moving around the organ and taking up bacteria on the way, a mechanism illustrated by analogy to the arcade game "Pac-Man". To test the "PacMan" idea, we performed simultaneous infections where we inoculated two Salmonella sseB mutants (expressing different LPS O antigens enabling the mutants to be differentially visualized by immunostaining in tissue sections) into the same animal. During the course of the infection the two strains remained segregated to different phagocytes and infection foci (Figure 3C), indicating that the high numbers of bacteria in each cell are not the result of a "Pac-Man" mechanism.

The most likely explanation for the high intracellular numbers of SPI-2 T3SS mutants is that there is replication and clonal expansion of an individual bacterium, and that therefore SPI-2 is not an absolute requirement for intra-macrophage replication of salmonellae.

\section{Similar net growth kinetics can be the result of very} different intracellular infection dynamics

To see whether these surprising intracellular bacterial growth dynamics underpin all attenuation of salmonellae in mice, we analyzed two other well-known and extensively described attenuated mutants. S12023 aroA (blocked in aromatic compound biosynthesis) and $\mathrm{S} 12023$ purA (deficient in purine metabolism) have very similar net growth characteristics to $\mathrm{S} 12023$ sseB (Figure 4A). Wild-type S12023 delivered at a similar dose to that used for the mutants exhibited low numbers of intracellular bacteria in livers and spleens throughout the infection (Figure 4BD), despite exhibiting rapid net growth per organ. At $48 \mathrm{~h}$ p.i. these mice were very close to death, with large numbers of extracellular bacteria and necrotic organs; however, those cells that remained infected still had an intracellular density lower than 

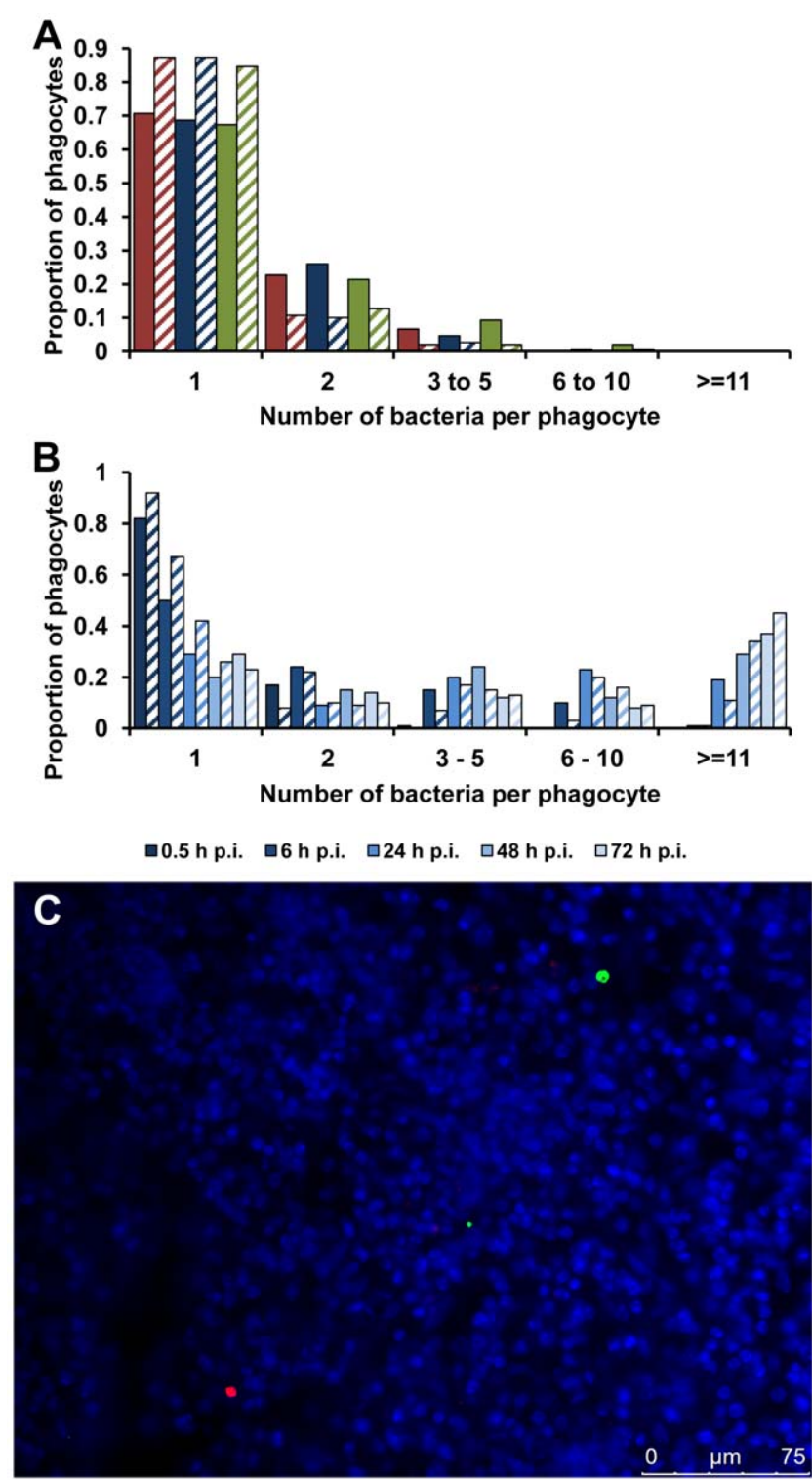

Figure 3. Accumulation of SPI-2 T3SS mutants inside cells is due to clonal expansion of a bacterium. (A) C57BL/6 mice were infected i.v. with $\sim \log _{10} 6.4 \mathrm{CFU}\left(=2.44 \times 10^{6} \mathrm{CFU}\right)$ of Salmonella S12023, $\sim \log _{10} 6.5 \mathrm{CFU}\left(=2.86 \times 10^{6} \mathrm{CFU}\right)$ of S12023 sseB, or $\sim \log _{10}$ $6.3 \mathrm{CFU}\left(=2.17 \times 10^{6} \mathrm{CFU}\right)$ of $\mathrm{S} 12023 \mathrm{sseB}$ (psseB). The proportion of infected phagocytes relative to the number of bacteria contained within each phagocyte is shown for livers (solid bars) and spleens (diagonal shading) at $0.5 \mathrm{~h}$ p.i. based on the counts obtained from 150 infected phagocytes per strain, from tissue obtained from 3 mice per strain [S12023 - red; S12023 sseB - blue; S12023 sseB(psseB) - green]. (B) C57BL/6 mice were infected i.v. with $\sim \log _{10} 6.4 \mathrm{CFU}\left(=2.64 \times 10^{6} \mathrm{CFU}\right)$ of $\mathrm{S} 12023 \mathrm{sseB}$. The proportion of infected phagocytes relative to the numbers of bacteria contained within each phagocyte is shown for livers (solid bars) and spleens (diagonal shading) at different time points between 0.5 and $72 \mathrm{~h}$ p.i. inclusive, based on the counts obtained from 100 infected phagocytes per organ, per time point, from tissue obtained from 4 mice per time point. (C) C57BL/6 mice were infected i.v. with $\sim \log _{10} 6.3 \mathrm{CFU}\left(=1.99 \times 10^{6} \mathrm{CFU}\right)$ of SL5559 sseB and SL5560 sse $B$ bacteria into the same animal via a single injection. Representative fluorescence micrograph of Salmonella SL5559 sseB and SL5560 sseB within phagocytes in an infected spleen at $72 \mathrm{~h}$ p.i. [SL5559 sseB (green), SL5560 sseB (red), nucleic acid is stained with DAPI (blue). Scale bar, $75 \mu \mathrm{m}]$.

doi:10.1371/journal.ppat.1003070.g003 that observed in heavily infected cells from mice infected with the S12023 sseB mutant at the same time point (Figure 4E). At each time point during the infection, the intracellular bacterial loads of the S12023 aroA and S12023 purA bacteria were heavily skewed towards low intracellular densities (Figure 4B-F, Figure S5 and Tables S1). Thus, similar net growth rates of salmonellae in organs can be derived from very different underlying intracellular growth dynamics (e.g. aroA mutant and purA mutant vs sseB mutant). We also generated double mutants, namely $\mathrm{S} 12023$ sseB aro $A$ and S12023 sseB purA. These exhibited an increasing number of cells containing large numbers of intracellular bacteria during the infection (Figure 4B-F, Figure S5 and Table S1). Thus, the intracellular bacterial loads of the double mutants followed the $s s e B$ mutant pattern.

We then examined the distribution of infected cells in the tissues for the aro $A$ and purA mutants and observed a small increase in the number of infected cells per field-of-view between 0.5 to $72 \mathrm{~h}$ p.i, for both S12023 aroA and S12023 purA, whereas for S12023 sseB aroA and S12023 sseB purA there was a small decrease in the number of infected cells per field-of-view over the same period of infection (Figures 4G and 4H, Figure S6 and Table S2). In other words the dispersion of the double mutants followed the sseB mutant pattern.

Finally, we co-infected mice with an $s s e B$ mutant and an aro $A$ mutant simultaneously and at the same dose (Figure S7A). The intracellular bacterial loads of the different bacteria were the same as those seen when the two strains are injected individually, with very low intracellular densities observed for the aro $A$ mutant and the characteristically higher densities for the $s s e B$ mutant (Figure S7B).

Overall the data show that very similar net growth kinetics can be the result of very different intracellular infection dynamics.

'Clusters' of SPI-2 mutant bacteria are not due to loss of SPI-2 T3SS-dependent cytotoxcity

Salmonellae induce host cell death during infection of cell cultures by several different mechanisms [29]. The exact contribution of each of these mechanisms to in vivo infection is far from clear. In vitro studies have demonstrated the involvement of SPI-2 T3SS effectors mediating cytotoxicity, namely SseL [30] and SpvB [31,32]. Recently a model has been proposed, which suggests that sseL and spo genes promote host cell apoptosis, enabling the bacteria to be taken up by other cells resulting in further intracellular replication $[29,30]$.

We considered whether the reduced spread and increased number of SPI-2 mutant bacteria inside host cells could be due to the loss of SPI-2 T3SS-dependent cytotoxicity. We generated single mutants in $s s e L, s p v B$ and an $s s e L s p v B$ double mutant, and looked at intracellular bacterial numbers in the livers and spleens of C57BL/6 mice infected with these strains (data not shown). With none of these mutants did we observe the heavily infected cells characteristic of the SPI-2 T3SS mutants, suggesting that the loss of secretion of SseL and/or SpvB in the SPI-2 mutant is not responsible for the increased number of SPI-2 mutant bacteria inside host cells.

Phagocyte NADPH oxidase inhibits Salmonella spread in the tissues in the absence of SPI-2 T3SS

In mammalian species, reactive oxygen radicals produced by the NADPH oxidase (Phox) are a major innate host defense mechanism against engulfed pathogens, including Salmonella [33,34]. The dynamic consequences of the interplay between Salmonella SPI-2 and the NADPH oxidase at the single cell level in 
A

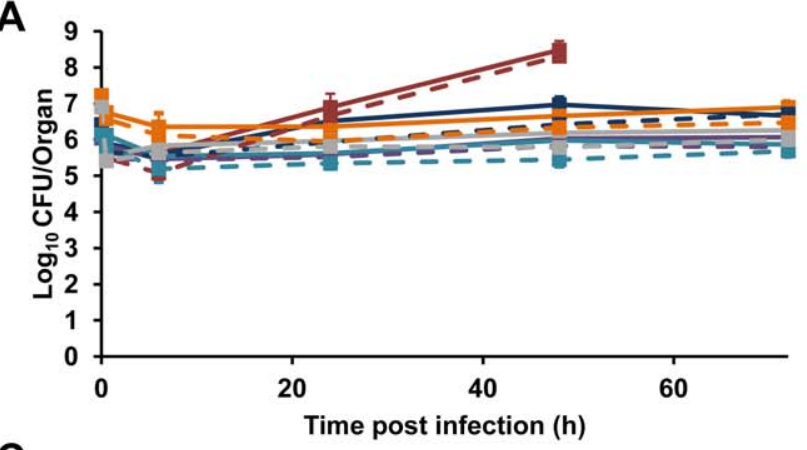

C

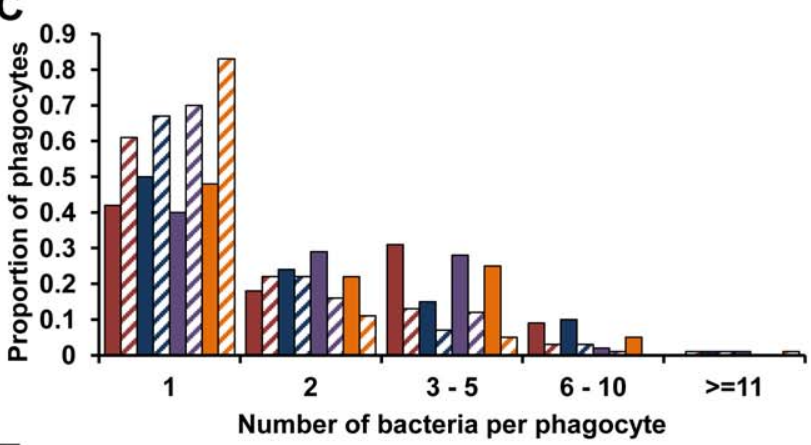

E

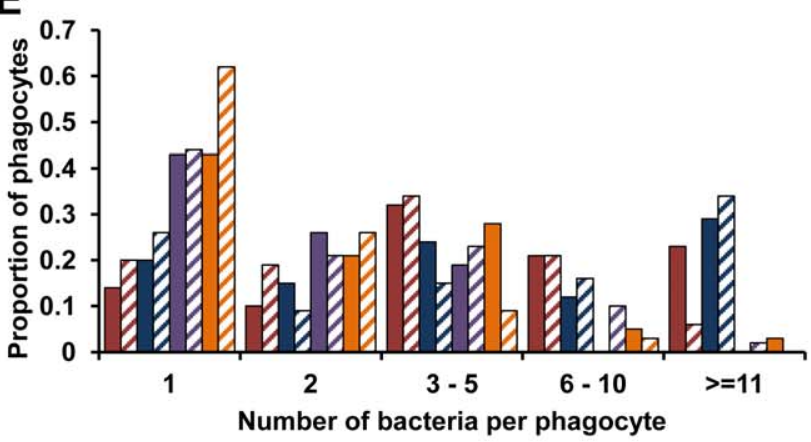

G

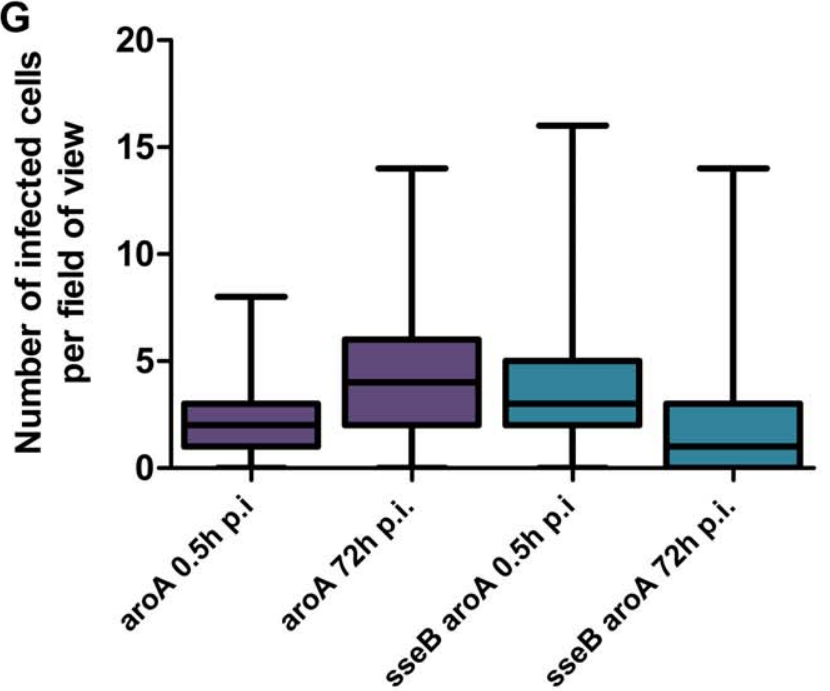

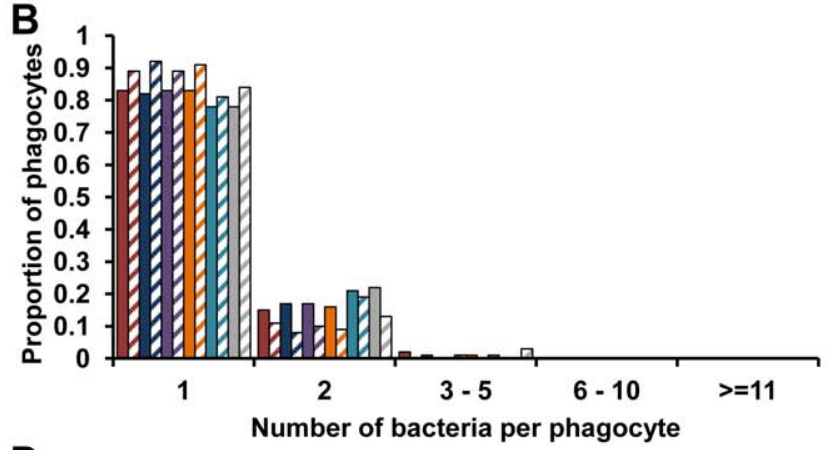

D

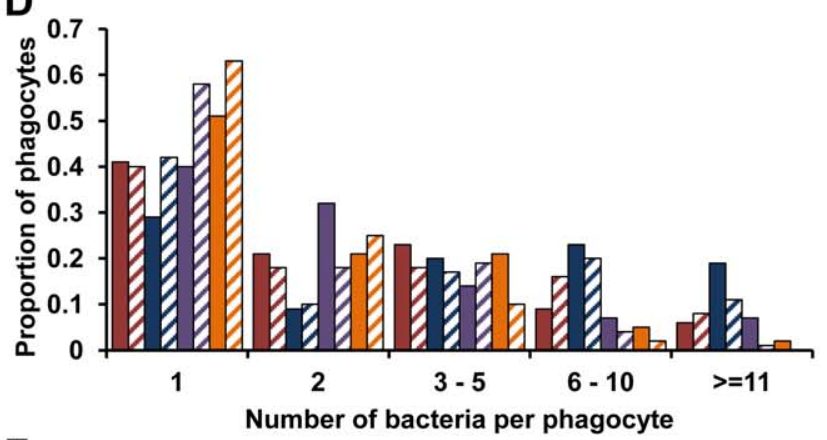

$\mathbf{F}$

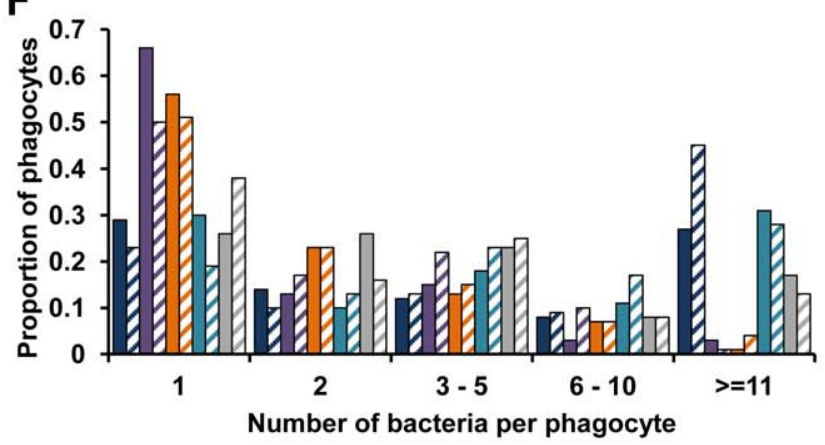

H

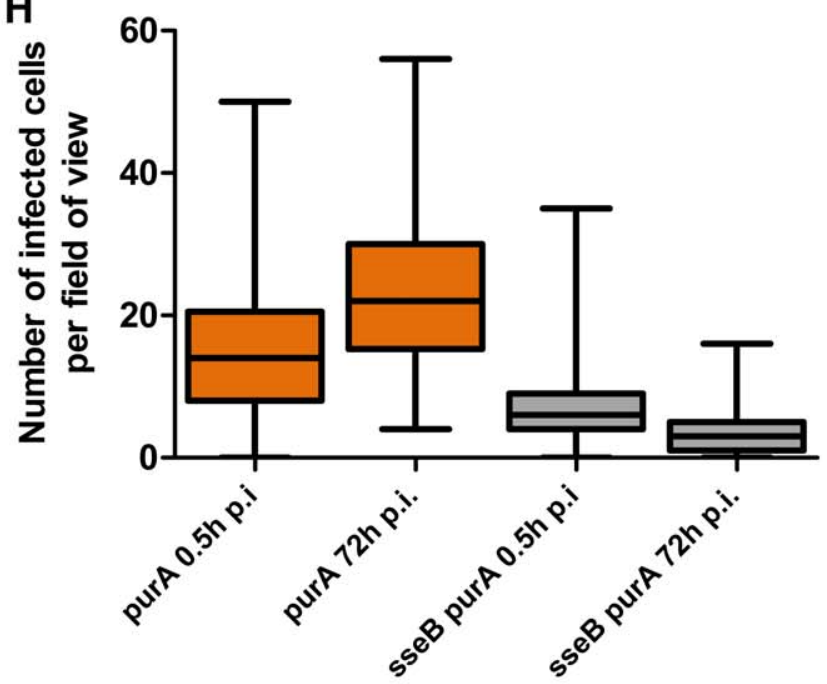

Figure 4. Similar net growth kinetics can be the result of very different intracellular infection dynamics. C57BL/6 mice were infected i.v. with $\sim \log _{10} 6.2 \mathrm{CFU}\left(=1.56 \times 10^{6} \mathrm{CFU}\right)$ of S12023, $\sim \log _{10} 6.4 \mathrm{CFU}\left(=2.64 \times 10^{6} \mathrm{CFU}\right)$ of S12023 sseB, $\sim \log _{10} 6 \mathrm{CFU}\left(=1.10 \times 10^{6} \mathrm{CFU}\right)$ of S12023 aroA, $\sim \log _{10} 7.2 \mathrm{CFU}\left(=1.69 \times 10^{7} \mathrm{CFU}\right)$ of S12023 purA, $\sim \log _{10} 6.1 \mathrm{CFU}\left(=1.37 \times 10^{6} \mathrm{CFU}\right)$ of S12023 sseB aroA, or $\sim$ Log $106.9 \mathrm{CFU}$ $\left(=7.93 \times 10^{6} \mathrm{CFU}\right)$ of $\mathrm{S} 12023 \mathrm{sseB}$ purA. (A) Net bacterial numbers in livers (unbroken lines) and spleens (dotted lines) were determined between 0.5 and $72 \mathrm{~h}$ p.i. inclusive. The net bacterial growth of $\mathrm{S} 12023 \mathrm{sseB}$ was obtained from 4 mice per time point, S12023 (high input dose) was obtained from 3 mice per time point at $0.5,6$ and $24 \mathrm{~h}$ p.i. and 6 mice at the $48 \mathrm{~h}$ p.i. time point, S12023 aroA, S12023 purA, S12023 sseB aroA and S12023 sseB purA was obtained from 3 mice per time point (results are expressed as mean $\log _{10}$ viable count \pm standard deviation) [S12023 - red; S12023 sseB - 
blue; S12023 aroA - purple; S12023 purA - orange; S12023 sseB aroA - light blue; S12023 sseB purA - grey]. (B-F) The proportion of infected phagocytes relative to the number of bacteria contained within each phagocyte is shown for livers (solid bars) and spleens (diagonal shading) at (B) 0.5 h p.i.; (C) 6 h p.i.; (D) 24 h p.i.; (E) 48 h p.i. and (F) 72 h p.i.. The intracellular bacterial distributions of each strain were based on the counts obtained from 100 infected phagocytes per organ, per time point, from tissue obtained from 3 mice per time point. (G and $H)$ Box and whisker plots showing the median, interquartile range and maximum and minimum number of infected cells per field-of-view in spleens at $0.5 \mathrm{~h}$ p.i. and $72 \mathrm{~h}$ p.i. for (G) S12023 aroA and S12023 sseB aroA, and (H) S12023 purA and S12023 sseB purA. The number of infected cells per field of view was obtained from 100 random fields from 3 mice for each strain at each time point. doi:10.1371/journal.ppat.1003070.g004

vivo are uncertain. gp91phox ${ }^{-/-}$mice lacking oxidase activity are fully susceptible to infection with SPI-2 mutants [33] and, in macrophages, a role has been ascribed to SPI-2 T3SS in the inhibition of the recruitment of the NADPH oxidase to the phagosome [35-37]. Recent studies have instead suggested a model in which Salmonella resistance relies on a range of detoxifying enzymes to cope with Phox-mediated oxidative stress [38].

To explore the cellular dynamics that underpin the interplay between SPI-2 and Phox in Salmonella, we infected C57BL/6 and gp9lphox ${ }^{-\prime-}$ mice with $\mathrm{S} 12023$ wild-type and its $s s e B$ mutant (Figure 5A). As expected, the net growth rates of both the wildtype and the mutant were greater in the gp91phox ${ }^{-/-}$mice than in wild-type C57BL/6 mice confirming previous observations that SPI-2 mutants can grow rapidly in the tissues in the absence of a functional NADPH oxidase [33].

Next we observed the intracellular bacterial densities of S12023 sseB in gp91 phox ${ }^{-1-}$ mice at the $48 \mathrm{~h}$ p.i. time point, and compared them to our earlier data using the same bacterial mutant in C57BL/6 mice. Unexpectedly, we found that the $s s e B$ mutant in the gp9lphox ${ }^{-/-}$mice was present at low numbers of bacteria per cell (Figure 5B, Figure S8 and Table S1), characteristic of wild-type Salmonella in a C57BL/6 mouse. Thus, in the absence of a functional NADPH oxidase the $s s e B$ mutant grew faster in the tissues, but did not accumulate within phagocytes.

Then we quantified the number of infected cells per field-of-view for the $s s e B$ mutant in C57BL/ 6 and gp91 phox ${ }^{-1-}$ mice throughout spleen tissues at $48 \mathrm{~h}$ p.i. (Figure 5C, Figure S9 and Table S2). The sseB mutant in the gp91phox ${ }^{-1-}$ mice had formed many more infection foci than the $s s e B$ mutant in $\mathrm{C} 57 \mathrm{BL} / 6$ mice despite there being similar total bacterial numbers in the tissues at this time (Figure 5A).

Taken together, these results suggest that in the absence of an active NADPH oxidase, SPI-2 T3SS becomes dispensable for the spread of Salmonella in the tissues as shown by increased numbers of infection foci and low intracellular densities of an $s s e B$ mutant in the gp91phox ${ }^{-1-}$ mice. Conversely, when an active NADPH oxidase is present a SPI-2 T3SS mutant grows inside cells to high intracellular densities but appears to be impaired in tissue spread and formation of new infection foci. The fact that an $s s e B$ mutant can escape from cells in the gp91phox ${ }^{-1-}$ mice also indicates that SPI-2 independent mechanisms can mediate escape from cells and that these as yet unidentified mechanisms/effectors are normally under the inhibitory effects of the NADPH oxidase in the absence of SPI-2. These results suggest a new interplay between SPI-2 T3SS and innate immunity in the dynamics of within-host bacterial growth and spread. Where NADPH-mediated mechanisms prevent bacterial escape from cells and at the same time exert bactericidal/bacteriostatic activity on the intracellular bacteria. However, we cannot rule out the possibility that the dynamics in the gp9lphox ${ }^{-1-}$ mice are an artifact of infection of the mutant mice with the mutant bacteria and may be proceeding by mechanisms different to natural murine infection.

\section{Discussion}

We have shown that intracellular Salmonella infection dynamics in vivo are dramatically altered by deletion of the SPI-2 T3SS in an unexpected way. Wild-type bacteria are present in low numbers per cell on average, and the rapid net growth of these bacteria in tissues coincides with escape from the intracellular environment and dispersal to new cells where new infection foci are established. On the other hand, mutants lacking SPI-2 T3SS seem unable to escape from the infected cell and by inference are therefore unable to disperse through the tissues. What is more, the SPI-2 T3SS mutants are able to grow to high numbers within the intracellular environment, which is not what has been reported as happening in many studies of infected macrophages in vitro. The observation that two variants of the Salmonella sseB mutant, which can be labelled either red or green, segregate to different infected cells upon simultaneous infection into the same animal provides strong evidence that in systemic Salmonella infections each infected cell and each multicellular infection focus is the product of the clonal expansion of a single founder bacterium. This also excludes the possibility that the mutant bacteria have accumulated intracellularly by phagocytosis. Therefore, even if a proportion of the bacteria were dead or dormant at the time of observation the high intracellular bacterial numbers observed in animals infected with the $s s e B$ mutants show that these mutants can and do grow to high numbers per cell as a result of intracellular division. Our results call into question the usefulness of in vitro systems for studying the natural history and dynamics of Salmonella infection of cells when these methods are used in isolation and not validated against what actually happens in the infected animal.

Another important observation from our study is that very similar net growth rates in organs can be derived from very different underlying intracellular growth dynamics. For example, slow growth of salmonellae per organ, typical of bacteria that are currently being trialed in humans as attenuated vaccine strains, can be generated by highly dispersed infections with low numbers of bacteria per cell, as is the case for aro $A$ mutant bacteria, or by relatively non-dispersed infections with high numbers of bacteria per cell, as we have shown here is the case for SPI-2 mutants.

That the phagocyte oxidase in involved in the restraint of spread of the salmonellae is a new concept, and suggests that this important innate immunity mechanism hampers bacterial escape from cells and at the same time (our previous work [33-35]) exerts antimicrobial functions on the intracellular bacteria.

Very high quality science has been published, concerning the dynamics of infectious disease spread through communities of people or animals, but much less work has been done to understand infectious disease dynamics within the host. Many conclusions about how infectious agents work are based on experiments in isolated monocultures of cells or in somewhat crude experiments in whole animals, where gross read-outs are used to try to capture what is a complex underlying process. Understanding this complex process at a more detailed level in whole animals is the next major challenge for infectious disease biologists, and is required if intervention strategies to prevent and cure infectious diseases are to be improved and targeted effectively. 


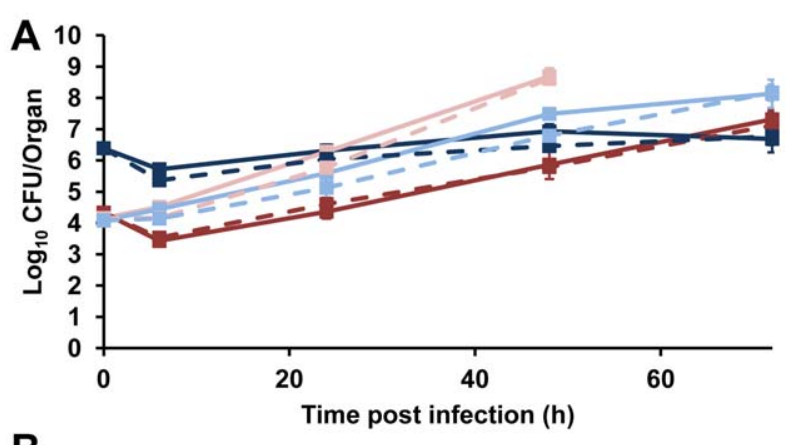

\section{B}
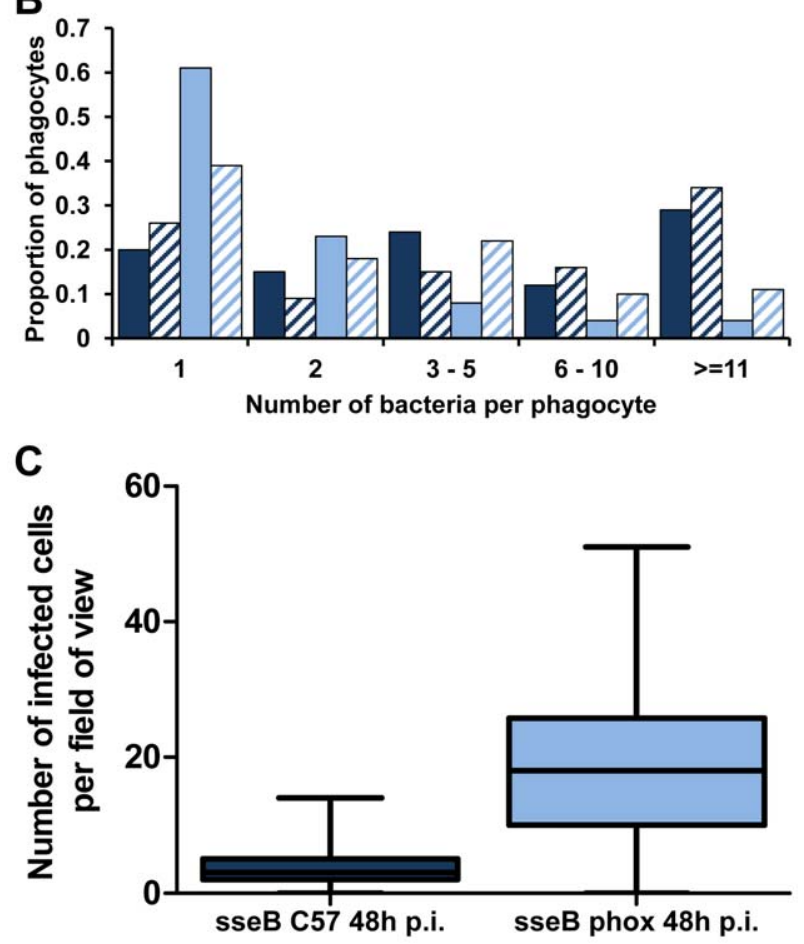

Figure 5. Phagocyte NADPH oxidase inhibits Salmonella spread in the tissues in the absence of SPI-2 T3SS. gp91phox ${ }^{-1}$ mice were infected i.v. with $\sim \log _{10} 4.2$ CFU $\left(=1.45 \times 10^{4}\right.$ CFU) of S12023 or $\sim \log _{10} 4.1 \mathrm{CFU}\left(=1.21 \times 10^{4} \mathrm{CFU}\right)$ of S12023 sseB, C57BL/6 mice were infected i.v. with $\sim \log _{10} 4.3 \mathrm{CFU}\left(=2.15 \times 10^{4} \mathrm{CFU}\right)$ of $\mathrm{S} 12023$ or $\sim \log _{10} 6.4 \mathrm{CFU}\left(=2.45 \times 10^{6} \mathrm{CFU}\right)$ of S12023 sseB. (A) Net bacterial numbers in livers (unbroken lines) and spleens (dotted lines) were determined between 6 and $72 \mathrm{~h} \mathrm{p.i.} \mathrm{inclusive} \mathrm{(results} \mathrm{are} \mathrm{expressed} \mathrm{as}$ mean $\log _{10}$ viable count \pm standard deviation), the net bacterial growth of S12023 and S12023 sseB in gp91 phox ${ }^{-1-}$ mice was obtained from 3 mice per time point (the data for S12023 and S12023 sseB in C57BL/6 mice is reproduced from Figure 1F. S12023 in C57BL/6 mice red; S12023 in gp91 phox ${ }^{-/-}$mice - pink; S12023 sseB in C57BL/6 mice dark blue; S12023 sseB in gp91phox ${ }^{-1-}$ mice - light blue). (B) The proportion of infected phagocytes relative to the numbers of bacteria contained within each phagocyte for $\mathrm{S} 12023 \mathrm{sseB}$ in gp91phox ${ }^{-1-}$ mice and S12023 sseB in C57BL/6 mice at $48 \mathrm{~h}$ p.i., based on the counts obtained from 100 infected phagocytes per organ, from tissue obtained from 3 mice per time point. (Livers - fully shaded; Spleens - diagonal shading). (C) Box and whisker plot showing the median, interquartile range and maximum and minimum number of infected cells per fieldof-view for S12023 sseB in C57BL/6 mice and S12023 sseB in gp91 phox $^{-1-}$ mice at $48 \mathrm{~h}$ p.i., from 100 random fields from 3 mice for each strain.

doi:10.1371/journal.ppat.1003070.g005

\section{Materials and Methods}

\section{Ethics statement}

All animals were handled in strict accordance with good animal practice as defined by the relevant international (Directive of the European Parliament and of the Council on the protection of animals used for scientific purposes, Brussels 543/5) and local (Department of Veterinary Medicine, University of Cambridge) animal welfare guidelines. All animal work was approved by the ethical review committee of the University of Cambridge and was licensed by the UK Government Home Office under the Animals (Scientific Procedures) Act 1986.

\section{Bacterial strains and growth conditions}

We used Salmonella enterica serovar Typhimurium strain NCTC S12023 (wild-type) (identical to ATCG 14028s) and mutant strains S12023 ssaV [39], S12023 sseB [5], S12023 sseB(psseB) [5], S12023 sseL [30], S12023 aroA (this study), S12023 purA (this study), S12023 sseB aroA (this study), S12023 sseB purA (this study), S12023 spiC (this study), S12023 ssaM (this study), S12023 spvB (this study) and S12023 sseL spvB (this study). We used $S$. Typhimurium C5, a highly virulent strain with an intravenous (i.v.) $\mathrm{LD}_{50}$ of $<10 \mathrm{CFU}$ in innately susceptible mice [40] and mutant strain C5 $\mathrm{ssaV}$ (this study). We used $S$. Typhimurium SL5559 and SL5560 which are sister transductants of $S$. Typhimurium C5 that differ only in $\mathrm{O}$ antigen type allowing their differential identification after immunostaining [41], and mutant strains SL5559 aroA (this study), SL5559 sseB (this study) and SL5560 sseB (this study). We used $S$. Typhimurium SL1344, a virulent wild-type strain which has an $\mathrm{LD}_{50}$ by the i.v. route of $<20 \mathrm{CFU}$ for innately susceptible mice [42], and mutant strain SL1344 ssaV (this study). Preparation of electrocompetent Escherichia coli and S. enterica cells and transformations were performed as previously described [43]. Bacteria were grown on Luria-Bertani (LB) medium. Media were supplemented with the appropriate antibiotic for selection (ampicillin $100 \mu \mathrm{g} / \mathrm{ml}$, kanamycin $50 \mu \mathrm{g} / \mathrm{ml}$ or chloramphenicol $10 \mu \mathrm{g} / \mathrm{ml})$. In vitro growth rates of Salmonella strains in LB broth were determined by both optical density and viable count.

\section{Recombinant DNA techniques}

Standard methods were used for molecular cloning [44]. Chromosomal and plasmid DNA purifications, and routine DNA modifications including restriction endonuclease digestion of DNA, modifications of DNA and ligations were carried out using commercial kits and supplies according to the manufacturers' instructions (QIAGEN, Crawley, UK; Promega, Southampton, UK; Invitrogen, Paisley, UK; Roche, Lewes, UK; New England Biolabs, Hitchin, UK). DNA concentration and purity were measured using a Nanodrop ND-1000 spectrophotometer. PCR primers were designed using Primer3 (http://frodo.wi.mit. edu/) and purchased from Sigma (Sigma-Genosys, UK). PCRs were performed in $25 \mu \mathrm{l}$ reaction volumes in $0.2 \mathrm{ml}$ Eppendorf tubes in a Perkin Elmer Gene Amp 2400 thermal cycler. Reactions contained $200 \mu \mathrm{M}$ dNTPs, $2 \mathrm{mM} \mathrm{Mg}^{2+}, 0.01$ volumes of Proof

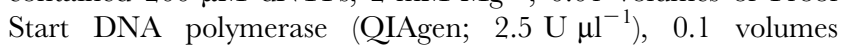
polymerase buffer $(10 \times), 1 \mu \mathrm{M}$ forward and reverse primers and template DNA ( $\sim 50 \mathrm{ng}$ plasmid DNA or $\sim 100 \mathrm{ng}$ chromosomal DNA). Thermal cycler conditions were $94^{\circ} \mathrm{C}$ for $10 \mathrm{~min}$, then 35 cycles of $94^{\circ} \mathrm{C}$ for $1 \mathrm{~min}, 55^{\circ} \mathrm{C}$ for $1 \mathrm{~min}$ and $72^{\circ} \mathrm{C}$ for $1 \mathrm{~min}$, followed by a final extension at $72^{\circ} \mathrm{C}$ for $10 \mathrm{~min}$.

\section{Generation of S. enterica mutants}

Mutants were generated using a modification of the ET-cloning procedure $[45,46]$ as previously described [47]. PCR was used to 
amplify the chloramphenicol resistance cassette from pACYC184 [48] or the kanamycin resistance cassette from pACYC177 [48] with 5' and 3' 60 bp homology arms complementary to the flanking regions of the gene to be deleted. Approx $1 \mu \mathrm{g}$ of linear PCR product was used for integration onto the chromosome using a modification of the Lambda Red method [49], as previously detailed [14]. Transformants were selected by plating onto media containing chloramphenicol or kanamycin. Screening for loss of the $\mathrm{pBAD} \lambda$ red helper plasmid was essentially as previously described [50], using MAST ID Intralactam circles (MAST Diagnostics, Bootle Merseyside, UK) to screen for the absence of beta-lactamase in bacterial colonies. (Further details of mutant constructions are provided in Supporting Information - Protocol S1).

\section{Mouse infections}

Sex- and aged-matched 9-12 week old C57BL/6 mice (Harlan Olac Ltd) and gp91 phox ${ }^{-/-}$mice (bred at the Wellcome Trust Sanger Institute, Hinxton, Cambridge, United Kingdom) were infected by intravenous (i.v.) injection of bacterial suspensions in a volume of $0.2 \mathrm{ml}$. Bacterial cultures were grown from single colonies in $10 \mathrm{ml}$ $\mathrm{LB}$ broth incubated overnight without shaking at $37^{\circ} \mathrm{C}$, then diluted in phosphate buffered saline (PBS) to the appropriate concentration for inoculation. Inocula were enumerated by plating dilutions onto LB agar plates. Mice were killed by cervical dislocation and the livers and spleens were aseptically removed and homogenized in sterile water using a Colworth Stomacher 80. The resulting homogenate was diluted in a 10-fold series in PBS and LB agar pour plates were used to enumerate viable bacteria.

\section{Immunostaining for microscopy}

Half of each organ was fixed overnight in $4 \%$ paraformaldehyde diluted in PBS, washed for $90 \mathrm{~min}$ in three changes of PBS and then immersed in 20\% sucrose in PBS for $16 \mathrm{~h}$ at $4^{\circ} \mathrm{C}$ before being embedded in Optimal Cutting Temperature (OCT) (Raymond A Lamb Ltd, Eastbourne, U.K.) in cryomoulds (Park Scientific, Northampton, U.K.). Samples were frozen and stored at $-80^{\circ} \mathrm{C}$. $30 \mu \mathrm{m}$ sections were cut, blocked and permeabilized for $10 \mathrm{~min}$ in a solution containing $10 \%$ normal goat serum and $0.02 \%$ Saponin in PBS (Sigma, Poole, UK). Subsequently sections were incubated with primary antibodies in permeabilizing solution, washed in PBS then incubated with secondary antibodies and observed using a fluorescence microscope (Leica DM6000B), or a confocal laser scanning microscope (Leica TCS SP5). Primary antibodies used in this study were: a 1:1000 dilution (Figures 1B, $1 \mathrm{C}, 1 \mathrm{D}, 1 \mathrm{E}, 2 \mathrm{~A}, 2 \mathrm{~B}, 2 \mathrm{C}, 3 \mathrm{~A}, 3 \mathrm{~B}, 4 \mathrm{~B}, 4 \mathrm{C}, 4 \mathrm{D}, 4 \mathrm{E}, 4 \mathrm{~F}, 4 \mathrm{G}, 4 \mathrm{H}$, $5 \mathrm{~A}, 5 \mathrm{~B}, 5 \mathrm{C}, \mathrm{S} 3 \mathrm{~B}$ and $\mathrm{S} 3 \mathrm{C}$ ), a 1:100 dilution (Figures $3 \mathrm{~B}$ and $\mathrm{S} 7 \mathrm{~B}$ ) of rat anti-mouse $\mathrm{CD} 18^{+}$monoclonal antibody (clone M18/2, BD Pharmingen); a 1:500 dilution (Figures 1B, 1C, 1D, 1E, 1G, 2A, 2B, 2C, 3A, 3B, 4B, 4C, 4D, 4E, 4F, 4G, 4H, 5B, 5C, S3B and $\mathrm{S} 3 \mathrm{C}$ ) of rabbit anti-LPS O4 agglutinating antiserum (Remel Europe Ltd); a 1:500 dilution (Figures 3C and S7B) of rabbit antiLPS O9 agglutinating serum (Remel Europe Ltd). Secondary antibodies used in this study were: a 1:100 dilution of Alexa Fluor 568-conjugated goat anti-rat antibody (Invitrogen-Molecular Probes, U.K.) and a 1:1000 dilution of Alexa Fluor 488conjugated goat anti-rabbit antibody (Invitrogen-Molecular Probes, U.K.) (Figures 1B, 1C, 1D, 1E, 1G, 2A, 2B, 2C, 3A, 3B, $4 \mathrm{~B}, 4 \mathrm{C}, 4 \mathrm{D}, 4 \mathrm{E}, 4 \mathrm{~F}, 4 \mathrm{G}, 4 \mathrm{H}, 5 \mathrm{~B}, 5 \mathrm{C}, \mathrm{S} 3 \mathrm{~B}$ and $\mathrm{S} 3 \mathrm{C})$. All sections were mounted onto Vectabond-treated glass slides (Vector Laboratories Ltd.) using Vectashield containing DAPI (Vector Laboratories Ltd.) for fluorescence microscopy and Fluoromount$\mathrm{G}$ (SouthernBiotech) for confocal microscopy. Intracellular bacterial distributions were counted by eye, from tissue obtained from multiple mice per group, as indicated in each Figure legend.

\section{Statistical analysis}

All data analysis was produced using the open-source $\mathrm{R}$ statistical language [51]. The MCMC routines were written in $\mathrm{C}$ and C++ utilizing the GNU GSL library [52]. The R package "coda" [53], was used to read in and summarize the output from the MCMC runs. Color palettes in the plots were obtained from the "RColorBrewer" package [54]. Data in the tables are given to 2 significant figures. (Further modeling detail is provided in Supporting Information - Protocol S1).

\section{Supporting Information}

Figure S1 Posterior means and 95\% credible intervals of intracellular bacterial distributions $(0.5 \mathrm{~h}$ p.i and $72 \mathbf{h ~ p . i . ) . ~ ( A ~ t o ~ F ) ~ B a r p l o t s ~ s h o w i n g ~ t h e ~ p r o p o r t i o n s ~ o f ~ i n f e c t e d ~}$ cells in each bacterial load category $(1,2,3-5,6-10$ and $\geq 11$ ) aggregated across mice but stratified by bacterial strain $[\mathrm{A}$ and $\mathrm{B}$, S12023 wild-type; C and D, S12023 sseB; and E and F, S12023 $s s e B($ psseB $)]$, organ (liver and spleen) and time post infection $(0.5 \mathrm{~h}$ p.i. and $72 \mathrm{~h}$ p.i.). The red bars correspond to the S12023 infections for (A) livers and (B) spleens, the blue bars to S12023 sse $B$ infections for $(\mathrm{C})$ livers and $(\mathrm{D})$ spleens, and the green bars to $\mathrm{S} 12023$ sseB(psseB) infections for (E) livers and (F) spleens. The darker shades correspond to the $0.5 \mathrm{~h}$ p.i. time point and the lighter shades to the $72 \mathrm{~h}$ p.i. time point. The marginal distributions for the probability of belonging to each group obtained from a hierarchical Bayesian ordinal regression model are represented by the posterior means and 95\% credible intervals (shown by the points and error lines).

(TIF)

Figure S2 Fitted negative binomial distributions against observed number of infected cells per field-of-view [wild-type, sseB, sseB(psseB)]. (A) S12023 at 72 h p.i., (B) S12023 sseB at $0.5 \mathrm{~h}$ p.i., (C) S12023 sseB at $72 \mathrm{~h}$ p.i., (D) S12023 sseB(psseB) at $72 \mathrm{~h}$ p.i.

(TIF)

Figure S3 SpiC is required for $S$. Typhimurium to disperse in the tissues. $\mathrm{C} 57 \mathrm{BL} / 6$ mice were infected i.v. with $\sim \log _{10} 6.3 \mathrm{CFU}\left(=1.89 \times 10^{6} \mathrm{CFU}\right)$ of $\mathrm{S} 12023$ spiC. (A) Net bacterial numbers in livers (unbroken line) and spleens (dotted line) were determined at time points between 0.5 and $72 \mathrm{~h}$ p.i. inclusive, from 4 mice per time point (results are expressed as mean $\log _{10}$ viable count \pm standard deviation). (B) The proportion of infected phagocytes relative to the numbers of bacteria contained within each phagocyte at 0.5 and $72 \mathrm{~h}$ p.i., based on the counts obtained from 100 infected phagocytes per organ, per time point, from tissue obtained from 4 mice per time point (Livers - fully shaded; Spleens - diagonal shading). (C) Box and whisker plot showing the median, interquartile range and maximum and minimum number of infected cells per field-of-view for $\mathrm{S} 12023 \mathrm{spiC}$ in spleens at 0.5 and $72 \mathrm{~h}$ p.i. obtained from 100 random fields from 4 mice at each time point. ( $\mathrm{D}$ and $\mathrm{E})$ Fitted negative binomial distributions against the observed data for the number of S12023 spiC infected cells per field of view, stratified by time (D) 0.5 h p.i. and (E) $72 \mathrm{~h}$ p.i.

(TIF)

Figure S4 Posterior means and 95\% credible intervals of intracellular bacterial distributions of $\mathrm{S} 12023 \mathrm{sseB}$. (A and B) Barplots showing the proportions of infected cells in each bacterial load category $(1,2,3-5,6-10$ and $\geq 11)$ aggregated across all mice but stratified by organ (A, liver and B, Spleen) and time $(0.5,6,24,48$ and $72 \mathrm{~h}$ p.i.). The shading gets lighter as time progresses. The marginal distributions for the probability of belonging to each group obtained from a hierarchical Bayesian 
ordinal regression model are represented by the posterior means and 95\% credible intervals (shown by the points and error lines). (TIF)

Figure S5 Posterior means and 95\% credible intervals of intracellular bacterial distributions of aroA and purA mutants. (A to D) Barplots showing the proportions of infected cells in each bacterial load category $(1,2,3-5,6-10$ and $\geq 11)$ aggregated across all mice but stratified by strain (S12023 sseB, S12023 aroA, S12023 purA, S12023 sseB aroA and S12023 sseB purA), organ (A and C, livers and B and D, spleens) and time (A and B, $0.5 \mathrm{~h}$ p.i. and $\mathrm{C}$ and $\mathrm{D}, 72 \mathrm{~h}$ p.i.). The blue bars correspond to $\mathrm{S} 12023$ sseB, the purple bars to $\mathrm{S} 12023$ aroA, the orange bars to $\mathrm{S} 12023$ purA, the light blue bars to $\mathrm{S} 12023$ sseB aroA and the grey bars to $\mathrm{S} 12023$ sseB purA. The marginal distributions for the probability of belonging to each group obtained from a hierarchical Bayesian ordinal regression model are represented by the posterior means and $95 \%$ credible intervals (shown by the points and error lines).

(TIF)

Figure S6 Fitted negative binomial distributions against observed number of infected cells per field-of-view (aro $A$ and purA). (A) S12023 aroA at $0.5 \mathrm{~h}$ p.i., (B) S12023 aroA at $72 \mathrm{~h}$ p.i., (C) S12023 purA at 0.5 h p.i., (D) S12023 purA at 72 h p.i., (E) S12023 sseB aroA at 0.5 h p.i., (F) S12023 sseB aroA at 72 h p.i., (G) S12023 sseB purA at 0.5 h p.i., (H) S12023 sseB purA at 72 h p.i.. (TIF)

Figure S7 Intracellular bacterial distributions of SL5559 aroA and SL5560 $\mathrm{sseB}$ in the organs of infected mice. (A and B) C57BL/6 mice were infected i.v. with $\sim \log _{10} 5.9$ colony forming units (CFU) $\left(=7.33 \times 10^{5} \mathrm{CFU}\right)$ of SL5559 aro $A$ and $\sim \log _{10} 6.0 \mathrm{CFU}\left(=9.20 \times 10^{5} \mathrm{CFU}\right)$ of SL5560 sseB bacteria via a single injection. (A) Net bacterial numbers in livers (unbroken line) and spleens (dotted line) were determined between 0.5 to $72 \mathrm{~h}$ p.i. (results are expressed as mean $\log _{10}$ viable count \pm standard deviation, from 3 mice per group, SL5559 aroA - purple; SL5560 sseB - blue). (B) Representative fluorescence micrograph of Salmonella SL5559 aroA and SL5560 sseB mutants (inoculated into the same animal via a single injection) within phagocytes in an infected spleen of a C57BL/ 6 mouse at 72 h p.i.. SL5559 aroA (green), SL5560 sseB (red), nucleic acid is stained with DAPI (blue). Scale bar, $75 \mu \mathrm{m}$. (TIF)

Figure S8 Posterior means and 95\% credible intervals of intracellular sseB distributions in wild-type and gp91 phox ${ }^{-1-}$ mice. (A to D) Barplots showing the proportions

\section{References}

1. Richter-Dahlfors AM, Buchan J, Finlay BB (1997) Murine Salmonellosis studied by confocal microscopy: Salmonella typhimurium resides intracellularly inside macrophages and exerts a cytotoxic effect on phagocytes in vivo. J Exp Med 186: 569-580.

2. Hindle Z, Chatfield SN, Phillimore J, Bentley M, Johnson J, et al. (2002) Characterization of Salmonella enterica derivatives harboring defined aro $C$ and Salmonella pathogenicity island 2 type III secretion system (ssaV) mutations by immunization of healthy volunteers. Infect Immun 70: 3457-3467.

3. Galan JE, Wolf-Watz H (2006) Protein delivery into eukaryotic cells and type III secretion machines. Nature 444: 567-573.

4. Ochman H, Soncini FC, Solomon F, Groisman EA (1996) Identification of a pathogenicity island required for Salmonella survival in host cells. Proc Natl Acad Sci USA 93: 7800-7804.

5. Hensel M, Shea JE, Waterman SR, Mundy R, Nikolaus T, et al. (1998) Genes encoding putative effector proteins of the type III secretion system of Salmonella pathogenicity island 2 are required for bacterial virulence and proliferation in macrophages. Mol Microbiol 30: 163-174

6. Cirrillo DM, Valdivia RH, Monack DM, Falkow S (1999) Macrophagedependent induction of the Salmonella pathogenicity island 2 type III secretion system and its role in intracellular survival. Mol Microbiol 30: 175-188.

7. Helaine S, Thompson JA, Watson KG, Liu M, Boyle C, et al. (2010) Dynamics of intracellular bacterial replication at the single cell level. Proc Natl Acad Sci USA 107: 3746-3751. of infected cells in each bacterial load category $(1,2,3-5,6-10$ and $\geq 11)$ aggregated across mice but stratified by bacterial strain [A and B, S12023 sseB in C57BL/6 mice; C and D, S12023 sseB in gp91phox ${ }^{-/-}$mice], organ (liver and spleen) (data in table S18). The red bars correspond to the $\mathrm{S} 12023$ sseB infections in C57BL/ 6 mice for (A) livers and (B) spleens, the blue bars to S12023 sseB infections in gp91phox ${ }^{-/-}$mice for $(\mathrm{C})$ livers and (D) spleens. The marginal distributions for the probability of belonging to each group obtained from a hierarchical Bayesian ordinal regression model are represented by the posterior means and 95\% credible intervals (shown by the points and error lines).

(TIF)

Figure S9 Fitted negative binomial distributions against observed number of infected cells per field-of-view, by mouse genotype. (A) S12023 sseB at 48 h p.i. in C57BL/6 mice, (B) S12023 sseB at $48 \mathrm{~h}$ p.i. in gp9lphox ${ }^{-/-}$mice.

(TIF)

Protocol S1 Details of $S$. enterica mutant generation, model constructions and statistical analyses.

(DOCX)

Table S1 Posterior means and 95\% credible intervals for proportional odds ratios from hierarchical Bayesian ordinal regression.

(DOCX)

Table S2 Differences between mean number of infected cells per field-of-view, from hierarchical Bayesian negative binomial regression.

(DOCX)

Table S3 Primer sequences used in this study. (DOCX)

\section{Acknowledgments}

S. Typhimurium strains S12023, S12023 ssaV, S12023 sseB, S12023 sseB(psseB) and $\mathrm{S} 12023$ sseL were kindly provided by Professor David Holden. gp91phox ${ }^{-/-}$mice were kindly provided by Dr Simon Clare.

\section{Author Contributions}

Conceived and designed the experiments: AJG DJM PM. Performed the experiments: AJG FJEM GLF PM. Analyzed the data: AJG TJM DJM PM. Wrote the paper: AJG DJM PM. Obtained the funding: AJG DJM PM.

8. Shea JE, Beuzon CR, Gleeson C, Mundy R, Holden DW (1999) Influence of the Salmonella typhimurium Pathogenicity Island 2 type III secretion system on bacterial growth in the mouse. Infect Immun 67: 213-219.

9. Salcedo SP Noursadeghi M, Cohen J, Holden DW (2001) Intracellular replication of Salmonella typhimurium strains in specific subsets of splenic macrophages in vivo. Cell Microbiol 3: 587-597.

10. Sheppard M, Webb C, Heath F, Mallows V, Emilianus R, et al. (2003) Dynamics of bacterial growth and distribution within the liver during Salmonella infection. Cell Microbiol 5: 593-600.

11. Brown SP, Cornell SJ, Sheppard M, Grant AJ, Maskell DJ, et al. (2006) Intracellular demography and the dynamics of Salmonella enterica infections. PLoS Biol 4: 2091-2098.

12. Grant AJ, Sheppard M, Deardon R, Brown SP, Foster G, et al. (2008) Caspase3-dependent phagocyte death during systemic Salmonella enterica serovar Typhimurium infection of mice. Immunol 125: 28-37.

13. Grant AJ, Foster GL, McKinley TJ, Brown SP, Clare S, et al. (2009) Bacterial growth rate and host factors as determinants of intracellular bacterial distributions in systemic Salmonella enterica infections. Infect Immun 77: 56085611 .

14. Grant AJ, Restif O, McKinley TJ, Sheppard M, Maskell DJ, et al. (2008) Modelling within-host spatiotemporal dynamics of invasive bacterial disease. PLoS Biol 6: e74. 
15. Mastroeni P, Grant AJ, Restif O, Maskell DJ (2009) A dynamic view of the spread and intracellular distribution of Salmonella enterica. Nat Rev Microbiol 7: 73-80.

16. Shea JE, Hensel M, Gleeson C, Holden DW (1996) Identification of a virulence locus encoding a second type III secretion system in Salmonella typhimurium. Proc Natl Acad Sci USA 93: 2593-2597.

17. Chakravortty D, Rohde M, Jager L, Deiwick J, Hensel M (2005) Formation of a novel surface structure encoded by Salmonella Pathogenicity island 2. EMBO J 24: 2043-2052.

18. Freeman JA, Rappl C, Kuhle V, Hensel M, Miller SI (2002) SpiC is required for translocation of Salmonella pathogenicity island 2 effectors and secretion of translocon proteins SseB and SseC. J Bacteriol 184: 4971-4980.

19. Yu X-J, Ruiz-Albert J, Unsworth KE, Garvis S, Liu M, et al. (2002) SpiC is required for secretion of Salmonella pathogenicity island 2 type III secretion system proteins. Cell Microbiol 4: 531-540.

20. Yu X-J, Liu M, Holden DW (2004) SsaM and SpiC interact and regulate secretion of Salmonella pathogenicity island 2 type III secretion system effectors and translocators. Mol Microbiol 54: $604-619$.

21. Yu X-J, McGourty K, Liu M, Unsworth KE, Holden DW (2010) pH sensing by intracellular Salmonella induces effector translocation. Science 328: 1040-1043.

22. Uchiya K, Barbieri MA, Funato K, Shah AH, Stahl PD, et al. (1999) A Salmonella virulence protein that inhibits cellular trafficking. EMBO J 18: 3924-3933.

23. Lee AH, Zareei MP, Daefler S (2002) Identification of a NIPSNAP homologue as host cell target for Salmonella virulence protein SpiC. Cell Microbiol 4: 739 750 .

24. Shotland Y, Kramer H, Groisman EA (2003) The Salmonella SpiC protein targets the mammalian Hook3 protein function to alter cellular trafficking. Mol Microbiol 49: 1565-1576.

25. Uchiya K, Groisman EA, Nikai T (2004) Involvement of Salmonella pathogenicity island 2 in the up-regulation of Interleukin-10 expression in macrophages: Role of protein kinase A signal pathway. Infect Immun 72: 1964-1973.

26. Uchiya K, Nikai T (2004) Salmonella enterica serovar Typhimurium infection induces cyclooxygenase 2 expression in macrophages: Involvement of Salmonella pathogenicity island 2. Infect Immun 72: 6860-6869.

27. Uchiya K, Nikai T (2005) Salmonella pathogenicity island 2-dependent expression of suppressor of cytokine signaling 3 in macrophages. Infect Immun 73: 55875594.

28. Uchiya K, Nikai T (2008) Salmonella virulence factor SpiC is involved in expression of flagellin protein and mediates activation of the signal transduction pathways in macrophages. Microbiol 154: 3491-3502.

29. Guiney DG, Fierer J (2011) The role of spo genes in Salmonella pathogenesis. Front Microbiol 2:129.

30. Rytkönen A, Poh J, Garmendia J, Boyle C, Thompson A, et al. (2007) SseL, a Salmonella deubiquitinase required for macrophage killing and virulence. Proc Natl Acad Sci USA 104: 3502-3507.

31. Libby SJ, Lesnick M, Hasegawa P, Weidenhammer E, Guiney DG (2000) The Salmonella virulence plasmid spo genes are required for cytopathology in human monocyte-derived macrophages. Cell Microbiol 2: 49-58.

32. Paesold G, Guiney DG, Eckmann L, Kagnoff MF (2002) Genes in the Salmonella pathogenicity island 2 and the Salmonella virulence plasmid are essential for Salmonella-induced apoptosis in intestinal epithelial cells. Cell Microbiol 4: 771781.

33. Mastroeni P, Vazquez-Torres A, Fang FC, Xu Y, Khan S, et al. (2000) Antimicrobial actions of the NADPH phagocyte oxidase and inducible nitric oxide synthase in experimental salmonellosis. II. Effects on microbial proliferation and host survival in vivo. J Exp Med 192: 237-248.

34. Vazquez-Torres A, Jones-Carson J, Mastroeni P, Ischiropoulos H, Fang FC (2000) Antimicrobial actions of the NADPH phagocyte oxidase and inducible nitric oxide synthase in experimental salmonellosis. I. Effects on microbial killing by activated peritoneal macrophages in vitro. J Exp Med 192: 227-236.
35. Vazquez-Torres A, Xu Y, Jones-Carson J, Holden DW, Lucia SM, et al. (2000). Salmonella pathogenicity island 2-dependent evasion of the phagocyte NADPH oxidase. Science 287: 1655-1658.

36. Gallois A, Klein JR, Allen L-AH, Jones BD, Nauseef WM (2001) Salmonella Pathogenicity island 2-encoded Type III Secretion System mediates exclusion of NADPH oxidase assembly from the phagosomal membrane. J Immunol 166: 5741-5748.

37. Vazquez-Torres A, Fantuzzi G, Edwards $3^{\text {rd }}$ CK, Dinarello CA, Fang FC (2007) Defective localization of the NADPH phagocyte oxidase to Salmonella-containing phagosomes in tumor necrosis factor p55 receptor-deficient macrophages. Proc Natl Acad Sci USA 98: 2561-2565.

38. Aussel L, Zhao W, Hebrard M, Guilhon AA, Viala JP, et al. (2011) Salmonella detoxifying enzymes are sufficient to cope with the host oxidative burst. Mol Microbiol 80: 628-640.

39. Deiwick J, Nikolaus T, Erdogan S, Hensel M (1999) Environmental regulation of Salmonella pathogenicity island 2 gene expression. Mol Microbiol 31: 1759-1773.

40. Hormaeche CE (1979) Natural resistance to Salmonella typhimurium in different inbred mouse strains. Immunol 37: 311-318.

41. Hormaeche CE, Mastroeni P, Harrison JA, Dermaco de Hormaeche R, Svenson S, et al. (1979) Protection against oral challenge three months alter i.v. immunization of BALB/c mice with live Aro Salmonella Typhimurium and Salmonella Enteritidis vaccines is serotype (species)-dependent and only partially determined by the main LPS O antigen. Vaccine 14: 251-259.

42. Hoiseth SK, Stocker BA (1981) Aromatic-dependent Salmonella typhimurium are non-virulent and effective as live vaccines. Nature 21: 238-239.

43. Dower WJ, Miller JF, Ragsdale CW (1988) High efficiency transformation of $E$. coli by high voltage electroporation. Nucl Acids Res 16: 6127-6145.

44. Sambrook J, Russell D (2001) Molecular cloning: a laboratory manual. 3rd edition. Cold Spring Harbour, New York: Cold Spring Harbor Laboratory Press.

45. Muyrers JPP, Zhang Y, Testa G, Stewart AF (1999) Rapid modification of bacterial artificial chromosomes by ET-recombination. Nucl Acids Res 27: 1555-1557.

46. Yu D, Ellis HM, Lee EC, Jenkins NA, Copeland NG, et al. (2000) An efficient recombination system for chromosome engineering in Escherichia coli. Proc Natl Acad Sci USA 97: 5978-5983.

47. Mo E, Peters SE, Willers C, Maskell DJ, Charles IG (2006) Single, double and triple mutants of Salmonella enterica serovar Typhimurium $\operatorname{deg} P(h t r A), \operatorname{deg} Q(h h o A)$ and $\operatorname{deg} S\left(h_{0} B\right)$ have diverse phenotypes on exposure to elevated temperature and their growth in vivo is attenuated to different extents. Microb Pathog 41: $174-182$.

48. Chang CY, Cohen SN (1978) Construction and characterization of amplifiable multicopy DNA cloning vehicles derived from the P15A cryptic miniplasmid. J Bacteriol 134: 1141-1156.

49. Datsenko KA, Wanner BL (2000) One-step inactivation of chromosomal genes in Escherichica coli K-12 using PCR products. Proc Natl Acad Sci USA 97: 66406645 .

50. Hautefort I, Proença MJ, Hinton JCD (2003) Single-copy green fluorescent protein gene fusions allow accurate measurement of Salmonella gene expression in vitro and during infection of mammalian cells. Appl Environ Microbiol 69: 7480-7491.

51. R Development Core Team (2006) R: A language and environment for statistical computing. R Foundation for Statistical Computing, Vienna, Austria. ISBN 3900051-07-0, URL http://www.R-project.org.

52. Galassi M, Davies J, Theiler J, Gough B, Jungman G, et al. (2009). GNU Scientific Library Reference Manual. 3rd edition. Available: http:www.gnu.org/ software/gsl/.

53. Plummer M, Best N, Cowles K, Vines K (2010) Coda: Output analysis and diagnostics for MCMC. R package version 0.14-2. http://CRAN.R-project. org $/$ package $=$ coda .

54. Neuwirth E (2007) RColorBrewer: ColorBrewer palettes. R package version 1.02. Available: erich.neuwirth@univie.ac.at 